\begin{tabular}{|l|l|}
\hline & \\
\hline &
\end{tabular}

SEÇÃO: VARIA

\title{
Uma apresentação dos conceitos de atitude e categoria em Eric Weil
}

\author{
A presentation of the concepts of attitude and category in Eric Weil \\ Una presentación de los conceptos de actitud y categoria en Eric Weil
}

\section{Daniel Benevides \\ Soares $^{1}$ \\ orcid.org/0000-0001-7275-9217 \\ benevides.soares@gmail.com}

Recebido em: 31/3/2020.

Aprovado em: 31/7/2020.

Publicado em: 12/01/2021.

\section{(c) (i)}

Artigo está licenciado sob forma de uma licença Creative Commons Atribuição 4.0 Internacional.
Resumo: O objetivo do presente trabalho é oferecer uma via de acesso ao pensamento de Eric Weil por meio da apresentação de alguns dos seus principais conceitos. Trata-se dos conceitos de atitude, categoria e retomada, elementos que constituem o léxico próprio do pensamento weiliano e cuja compreensão é capital para o enfrentamento de sua principal obra, a Lógica da filosofia. Oferece-se no presente artigo uma explanação introdutória sobre algumas das ferramentas conceituais fundamentais para a pesquisa na filosofia weiliana. Para tanto, dividiu-se o artigo em três seções. Na primeira, introduziu-se a discussão weiliana a respeito da filosofia e do seu outro, a violência, bem como de uma lógica da filosofia. Encerra-se essa etapa apresentando informações importantes sobre as categorias weilianas. Na segunda seção, discute-se de modo mais detido as categorias e as atitudes, suas dinâmicas e a passagem entre elas. Diferenciam-se atitudes reais das atitudes puras, aquelas que geram as categorias. Na terceira seção, tratamos do conceito de retomada. Conclui-se essa seção com as categorias formais que esquematizam a lógica da filosofia e realizam a transição do formal para o concreto: sentido e sabedoria.

Palavras-chave: Atitude. Categoria. Retomada. Lógica da filosofia.

Abstract: This paper seek to offer a way of accessing Eric Weil's thought through a presentation of some of his main concepts. These are the concepts of attitude, category and resumption, elements that constitute the lexicon proper to Weil's philosophy and whose understanding is crucial for facing his main work: Logique de la philosophie. An introductory explanation of some of the fundamental conceptual tools for research in weilian philosophy is offered in this article. the article was divided into three sections. In the first, we introduce the Weilian discussion about philosophy and its other, violence, as well as a logic of philosophy. We ended this stage by presenting important information about the Weilian categories. In the second section we discuss more closely the categories and attitudes, their dynamics and the passage between them. Real attitudes are differentiated from pure attitudes, those that generate categories. In the third section, we present the concept of resumption. We conclude this section with the formal categories that outline the logic of philosophy and make the transition from formal to concrete: meaning and wisdom. En la segunda sección, las categorias y actitudes, su dinámica y el paso entre ellas se discuten más de cerca. En la tercera sección, tratamos el concepto de reanudación.

Keywords: Attitude. Category. Resumption, Logic of philosophy.

Resumen: El objetivo de este trabajo es ofrecer una forma de acceder al pensamiento de Eric Weil a través de una presentación de algunos de sus conceptos principales. Estos son los conceptos de actitud, categoria y reanudación, elementos que constituyen el léxico propio del pensamiento weiliano y cuya comprensión es esencial para enfrentar su trabajo principal, la lógica de la filosofia. En este artículo se ofrece una explicación introductoria de algunas de las herramientas conceptuales fundamentales para la investigación en filosofia weiliana. Con este fin, el artículo se dividió en tres secciones. En el primero, se 
introdujo la discusión weiliana sobre la filosofía y su otra, la violencia, asi como una lógica de la filosofía. Esta etapa finaliza con la presentación de información importante sobre las categorias weilianas. Las actitudes reales se diferencian de las actitudes puras, aquellas que generan categorias. sta sección concluye con las categorias formales que describen la lógica de la filosofía y hacen la transición de lo formal a lo concreto: significado y sabiduria.

Palabras clave: Actitud. Categoria. Reanudado. Lógica de la filosofia

\section{Introdução}

A Lógica da filosofia compõe o centro do pensamento weiliano. Apresentando uma compreensão dos diversos discursos filosóficos possiveis, para ter acesso a essa obra é necessário familiarizar-se com conceitos fundamentais que integram o léxico weiliano. Conceitos como atitude, categoria, retomada, dados na articulação entre filosofia e violência, bem como o entendimento do que o autor considera como uma lógica da filosofia são elementos indispensáveis um contato com a obra de Eric Weil. O passo inicial, como uma propedêutica para a Lógica da filosofia, encontra-se no tratamento da relação entre a filosofia e aquilo que Weil denomina como seu outro: a violência. $O$ objetivo do presente artigo é fazer uma apresentação desses conceitos do pensamento weiliano, objetivando assim contribuir para a leitura dessa obra central para o pensamento do autor.

\section{Filosofia e violência: uma lógica da filosofia}

No pensamento weiliano existe um motor para a discussão filosófica. Trata-se daquele que é o seu problema fundamental. Segundo Kirscher (1992, p. 141), a violência é o problema constitutivo da filosofia e todos os discursos filosóficos são impelidos por esse problema.

Não nos importa, aqui, saber em que direção este impulso agiu nos diferentes sistemas, e tampouco nos importa que se tenha ou não reconhecido a violência (sob outros nomes, entenda-se) como o que é irredutivel no homem, que se tenha feito da realização da não violência na existência do homem o objetivo desse discurso: essas escolhas são apenas os derivados da escolha primordial, aquela entre violência e discurso - escolha primordial porque anterior a todo discurso para o próprio discurso, se ele quiser se compreender (WEIL, 2012, p. 90, grifo do autor).

A violência pode receber outros nomes, mas ainda será o motor da filosofia. ${ }^{2}$ Desse modo, a experiência que se manterá perpetuamente como objeto do esforço filosófico de Weil será a da história e aquela das múltiplas formas de violência que assinalam a realidade humana, o que inclui a violência social e moral, mas igualmente a sua manifestação política (CANIVEZ, 1999, p. 10). Para compreendermos no que consiste a violência para Weil, esse duplo da razão, é essencial não perdermos de vista o seu caráter multifacetado. Isso porque a violência é um Proteus, ou seja, ela é mutável, apresentando-se em formas distintas ao longo dos tempos (WEIL, 2003, p. 9). Podemos falar de uma violência interior, aquela decorrente da vida moral, de uma violência exterior, aquela da natureza, mesmo de uma violência que é negação consciente da razão. ${ }^{3}$ Desse modo, a violência pode ser compreendida de maneiras diversas, o que não nos impede de apontar alguns de seus traços característicos. A violência é a recusa da verdade, do sentido, da coerência e a escolha do ato negador, da linguagem incoerente, do discurso técnico que serve sem se perguntar para quê. Podemos entendê-la como o silêncio e a expressão do sentimento pessoal e que se pretende pessoal (WEIL, 2012, p. 99). Por essência, a violência se opõe à compreensão (WEIL, 1970, p. 362).

A violência trata-se da recusa do discurso e da razão, a recusa da compreensão e da comunicação segundo a linguagem informada pela razão, a recusa da comunidade humana mediatizada segundo a exigência da verdade (KIRSCHER, 1992, p. 38).

A violência é originária, radical e irredutivel (QUILLIEN, 1970, p. 407). Ela marca o movimento de oposição da filosofia contra aquilo que é seu

\footnotetext{
2 "A morte é o gênio inspirador, a musa da filosofia... Sem ela, dificilmente ter-se-ia filosofado" (SCHOPENHAUER, 2014, p. 85). "Eu - esse individuo específico - posso deixar a via do discurso coerente, posso seguir a via da violência (que Descartes designava sob o nome de vontade [...]" (WEIL, 2012, p. 100).

3 Conferir a esse respeito Caillois (1984, p. 214).
} 
outro, o outro do discurso. "O 'outro' do discurso em Weil, nunca é exagerado insistir, é a violência, e o primeiro desafio é, portanto, compreendê-la, mas não só isso, afinal não deixaria de ser violência depois de compreendida" (CASTELO BRANCO, 2016, p. 177). Ela encontra-se radicada no mundo e ela constitui sempre uma vereda que permanece convidativa ao ser humano. Desse modo, esse outro da razão permanece sempre como uma possibilidade do homem, sempre susceptivel de eclodir, dando provas que o homem pode recusar o discurso coerente e retornar sempre à barbárie (QUILLIEN, 1970, p. 402).

$A$ violência, no que pese o fato de constituir sempre uma possibilidade, não é sequer um dado, um pressuposto, senão para o ser que não é apenas violência (PERINE, 1987, p. 136). Trata-se, nesse caso, daquele ser que não quer ser violento: o filósofo. Importa ponderar que o filósofo e o violento não são de espécies diferentes, apenas o mesmo ser humano que recusou ou aceitou uma possibilidade aberta a todos sem exceção. Ninguém é filósofo. Recusar a violência permanece sempre como um esforço livre e contínuo de atualização (KIRSCHER, 1992, p. 35). A filosofia busca compreender a violência para poder fazer frente a ela. Trata-se do discurso que compreende a si mesmo enquanto o discurso de um ser para o qual sempre permanece aberta outra possibilidade: a violência, possibilidade essa realizada em primeiro lugar, o que significa dizer que o homem forma seu discurso na violência, contra a violência (WEIL, 2012, p. 104-105). É de acordo com esse entendimento que Weil fala de um segredo da filosofia: para além da necessidade de compreensão, a filosofia quer que o seu outro desapareça do mundo (CASTELO BRANCO, 2016, p. 177).

A filosofia indica um sentido segundo o qual ele avalia todas as coisas, as julga e decide seu lugar (WEIL, 1970, p. 361). Desse modo, ela não possui um domínio restrito, reservando-se o direito de falar de tudo segundo a lógica do diálogo (WEIL, 1970, p. 355). Essa lógica do diálogo que procura compreender as possibilidades tanto do próprio discurso quanto daquilo que the faz oposição, a violência, constitui a lógica da filosofia. A obra central do corpus weiliano, não por acaso, é intitulada Lógica da filosofia. Nessa obra, para se realizar a compreensão do caráter incompreensível da violência, confere-se a ela uma linguagem da qual ela não faz uso (PERINE, 1987, p. 175). "É, pois, por um artificio de prosopopéia que o lógico da filosofia elabora o discurso da violência, sem, contudo, perder a consciência metódica do seu artificio" (PERINE, 1987, p. 176, grifo do autor).

$\mathrm{Na}$ Lógica da filosofia encontramos o desenvolvimento das diversas possibilidades discursivas da filosofia no seu movimento. A compreensão desse movimento possibilita que se fale de uma lógica dos discursos filosóficos, ou seja, uma lógica da filosofia. Temos então uma elaboração do discurso coerente que se compreende compreendendo seus próprios pressupostos e que se realiza ao desenvolver a sucessão dos discursos coerentes do homem (QUILLIEN, 1970, p. 405). É importante frisar que uma lógica da filosofia não é lógica no sentido da não contradição, pois suas atitudes e categorias trazem soluções contraditórias entre si. Não é também lógica da ciência, pois reconhece que a ciência é uma entre as possibilidades do homem. É logos do discurso eterno em sua historicidade, compreendido como uma possibilidade humana por ele próprio (WEIL, 2012, p. 115). Segundo Caillois (1953, p. 281) essa fórmula weiliana comporta três aspectos. Primeiro, que a lógica compreende os diversos discursos coerentes que se querem eternos e que o são, pois estão presentes no logos final, que os compreende em sua aparição sucessiva, enquanto produtos de atitudes assumidas por pessoas na história. Segundo, que esse logos se compreende enquanto tal, enquanto uma possibilidade livre da escolha do discurso frente ao seu outro: a violência. Terceiro, que os fatos se tornam inteligiveis no logos que os reflete e que, por sua vez, o logos se encarna e é experimentado nos fatos. "Ela compreende a tudo e a si mesma, porque compreende o homem na filosofia, a filosofia no homem; porque compreende a coerência na violência e a violência no discurso coerente" (WEIL, 2012, p. 127).

Os discursos humanos buscam compreender 
o mundo e a vida. A tarefa da lógica da filosofia, enquanto busca por descobrir o sentido das compreensões do mundo expressos nos discursos, é a de realizar uma compreensão da compreensão. Para isso Weil utiliza os conceitos de atitude e de categoria (PERINE, 1987, p. 136). Essa compreensão se dá segundo as diferentes formas que o discurso filosófico pode assumir, ou seja, a lógica da filosofia é composta de diversas atitudes e categorias. Atitudes elegem o que lhes é essencial, recusando o que thes é inessencial. Não aceitam, desse modo, tudo que lhes é dado, formando discursos coerentes, o que constitui suas respectivas categorias. A sucessão desses discursos tem como fio condutor a ideia de um discurso coerente que compreende a si mesmo: a lógica da filosofia (WEIL, 2012, p. 109).

A Lógica da filosofia, portanto, é o desenvolvimento das categorias puras e trans-históricas do discurso que fundam, na sua articulação, a compreensibilidade de fato e direito de todos os discursos concretos efetivamente tidos na história (TOSEL, 1981, p. 1156). A trans-historicidade das categorias significa que elas são constitutivas das possibilidades para o discurso filosófico. Não obstante, o desenvolvimento delas se dá enquanto realização humana, ou seja, enquanto atitudes, o que significa que a dinâmica das categorias se dá na história.

Cabe à filosofia dizer quais são as categorias fundamentais, essas possibilidades de organizar discurso, existência e mundo em torno de um essencial, possibilidades realizadas na história do homem, e cabe-lhe também insistir no fato de que essas categorias precedem, para ela, as atitudes que têm precedência na história: ela organiza as categorias com vistas à coerência absoluta que compreende a si mesma como possibilidade do homem, e é por isso que, advertida pela possibilidade da revolta contra todo discurso coerente, ela sabe também que sua construção vale apenas para ela (WEIL, 2012, p. 118, grifo do autor).

É o conjunto das categorias que permite a ideia de uma lógica da filosofia enquanto sucessão dos discursos nos quais o homem compreendeu as suas realizações e se compreendeu nas suas realizações. Trata-se de mostrar como o discurso se forma na história a partir de uma atitude que o indivíduo não é obrigado a deixar; de como aquilo que é implicitamente reconhecida pela atitude chega a sua consciência. O esquema de sucessão das categorias é necessário, mas apenas para a lógica da filosofia. A realidade não necessariamente segue o esquema de sucessão das categorias que é legítimo para a lógica da filosofia (PERINE, 1987, p. 138-139). A passagem de uma atitude para outra se dá por meio de uma ruptura livre, de modo que para se chegar a uma determinada atitude, não necessariamente um indivíduo deve passar pela atitude anterior conforme descrito na lógica. A ultrapassagem de uma atitude não se justifica no discurso daquele mundo; tal ultrapassagem é ali incompreensível, só deixando de sê-lo a partir de outra atitude, quando a categoria que se forma captar na sua coerência parcial aquela que ultrapassou (PERINE, 1987, p. 140).

A lógica da filosofia é a categoria das categorias, o centro organizador não somente dos discursos, mas do discurso (WEIL, 2012, p. 127). Isso significa que ela é filosofia primeira porque é nela que todas as atitudes e as categorias são compreendidas no seu sentido (WEIL, 2012, p. 110).

A Lógica da filosofia de Weil apresenta 18 atitudes - categorias, sendo 16 delas concretas e duas formais. São elas: verdade, não sentido, verdadeiro e falso, certeza, discussão, objeto, eu, Deus, condição, consciência, inteligência, personalidade, absoluto, obra, finito, ação, sentido e sabedoria. As chamadas categorias antigas vão da verdade até Deus. Da condição ao absoluto temos as categorias modernas. Obra, finito e ação marcam a revolta contra o discurso absolutamente coerente. Essas são as categorias concretas. As duas últimas, sentido e sabedoria, são as categorias formais. Antes de nos determos mais pormenorizadamente nas definições de atitudes e de categorias, convém desfazer algumas confusões que podem permear esses conceitos weilianos.

Em primeiro lugar, convém esclarecer que as categorias weilianas, não são categorias na acepção habitual que designa substância, causa etc.; não são categorias metafísicas e sim filosóficas. As primeiras, também tomadas como metacientíicas, são aquelas pelas quais a filosofia dá conta da pos- 
sibilidade ou atividade da ciência. Já as categorias filosóficas são formas do discurso que definem os pontos de vista logicamente possiveis sobre o real. As categorias metafísicas têm lugar nas categorias filosóficas, de modo que o emprego e o sentido das categorias metafísicas variam de acordo com a categoria filosófica no seio da qual cada uma delas aparece (CANIVEZ, 1999, p. 35). Existe, portanto, uma importante diferença entre categorias metafísicas e categorias filosóficas. Sob as primeiras, entende-se os conceitos fundamentais determinando as questões segundo as quais deve-se considerar, analisar ou questionar aquilo que se quer saber no que é. Já as segundas são as ideias centrais dos discursos a partir das quais uma atitude se exprime de maneira coerente (KIRSCHER, 1999, p. 151).

Em segundo lugar convém pontuar que a categoria expressa o essencial de uma determinada atitude como um discurso coerente. Entretanto, vale acrescentar que esse discurso, se é tradicionalmente aquilo que se chama um sistema, não é, contudo, sistema filosófico no sentido ocidental, não o é necessariamente, nem o será habitualmente (WEIL, 2012, p. 114).

Em terceiro lugar, deve-se ter em mente que nenhuma categoria exaure um pensador, de modo que, por exemplo, o pensamento de Hegel não pode ser reduzido apenas à categoria do absoluto, ou o de Nietzsche à personalidade, o de Platão ao objeto ou o de Agostinho à Deus - embora todas essas categorias sirvam para a compreensão dos pensadores em questão, trata-se de evitar uma visão reducionista. A categoria representa o conceito que organiza um pensamento filosófico. Mas a filosofia de um determinado pensador não se esgota em uma determinada categoria; ela é complexa, combinando diferentes formas de coerência, entrecruzando vários tipos de discurso. Para analisar uma filosofia concreta, deve-se recorrer a diferentes categorias como uma combinação de pontos de vista lógicos distintos. Uma filosofia mobiliza um conjunto de categorias do discurso por meio de uma retomada dessas categorias sob aquela que realiza a sua coerência (CANIVEZ, 1999, p. 57-58).
Finalmente, existe uma distinção entre a sucessão lógica e a sucessão histórica das atitudes e categorias. As categorias coexistem no discurso uno, formando, do ponto de vista lógico, uma lógica da filosofia. Entretanto, no tempo, as categorias se sucedem. Isso ocorre ainda que a filosofia nasça como um todo, ou seja, completa, de tal modo que todas as atitudes e as categorias se encontram nela presentes. Não obstante, as categorias só são pensadas como tais, enquanto categorias ao cabo da evolução da filosofia, que é sua autocompreensão, no decurso da qual as categorias então se mostram em sua autonomia relativa. É a sequência histórica dos sistemas que mostra as categorias. Uma categoria pode elaborar-se em oposição à atitude-categoria que lhe antecede logicamente. Isso acontece sem que a atitude que se opõe tenha formado seu discurso de modo a constituir uma categoria pura (WEIL, 2012, p. 603-606). A passagem de uma categoria à outra é livre, arbitrária. Do ponto de vista da categoria que é ultrapassada, essa passagem é violenta. Sob a perspectiva da nova atitude, entretanto, a recusa se mostrará como justificável posteriormente como uma nova determinação da razão (KIRSCHER, 1992, p. 49-50).

\section{Atitude e categoria: movimentos da filosofia}

Os discursos buscam compreender o mundo e a vida. A tarefa da lógica da filosofia, enquanto busca por descobrir o sentido das compreensões do mundo expressos nos discursos humanos, é a de realizar aquilo que podemos denominar como uma compreensão da compreensão. Para isso Weil utiliza os conceitos de atitude e de categoria (PERINE, 1987, p. 136). Na lógica do discurso weiliano, encontram-se duas possibilidades: uma que é considerada lógica e outra que é real. A possibilidade lógica é a categoria. Ela é uma forma de coerência que define umas das possibilidades do discurso. Mas a cada possibilidade lógica corresponde uma possibilidade real: a atitude. Trata-se aqui daqueles que de fato vivem no e pelo discurso. Para aqueles que existem na atitude, a referida categoria constitui 
o conceito central no qual se organza sua ligação com o mundo e consigo mesmo (CANIVEZ, 1999, p. 32). Podemos entender que a atitude é o sentido vivido e a categoria é o sentido pensado (CANIVEZ, 2013, p. 15).

Na sua relação, categoria e atitude tratam, respectivamente, dos diferentes discursos possiveis que dão conta das variadas formas de vida assumidas pelos homens na história (CAILLOIS, 1977, p. 1). Para o indivíduo da vida existem apenas atitudes, as categorias primam na perspectiva filosófica. Ambas, porém, permitem tanto compreender os seres humanos quanto à humanidade compreender-se (WEIL, 2012, p. 108). Desse modo, as atitudes são as diferentes formas que os indivíduos concretos adotam para negar aquilo que para eles é o outro e que tomam consciência de si mesmas nos tratados dos filósofos que se esforçam para compreendê-las como categorias. Assim sendo, podemos dizer que uma categoria é o conceito organizador que confere sentido a tudo aquilo que existe para os individuos da respectiva atitude, sendo o princípio fundamental a partir do qual essa mesma atitude se exprime de forma coerente. Enquanto desenvolvimento da atitude, a categoria fala a linguagem correspondente ao bom senso de sua época para aquele que vive segundo ela (QUILLIEN, 1970, p. 414). Uma atitude, portanto, é uma maneira fundamental e irredutivel de se viver, agir e compreender. Uma categoria filosófica é o discurso próprio implícito em cada atitude. Filosofar em cada atitude trata-se de visar a explicação daquilo que está implícito, de modo que se busca elevar-se da linguagem tida como natural da atitude ao discurso explícito da categoria (KIRSCHER, 1999, p. 147).

$A$ atitude enquanto conceito weiliano não deve ser confundida com a descrição de um tipo de comportamento psicológico, sociológico, histórico etc. (KIRSCHER, 1989, p. 163). Segundo Costeski, uma definição adequada para a atitude weiliana seria a héxis aristotélica, na acepção de virtudes, uma héxis intelectual, um estilo de vida. A héxis seria uma disposição estável, a posse de determinadas virtudes, disposições do corpo e da alma. A héxis engloba, ainda, a ação interme- diária entre um possuidor e um possuido - entre possuir um carro e o motorista existe a ação de possuir o veículo (2009, p. 31-33).

O individuo vive na sua atitude e ela é o que ele vive: trata-se da vida mesma do ser humano, aquilo que the parece como natural e que, justamente por sê-lo, não é necessariamente pensada por ele. Aquele que nela vive pode seguir a vida na sua atitude sem querer compreendê-la em um discurso. Mas, a partir do momento que ele o faz, captando o seu essencial, ele formula uma categoria (PERINE, 1987, p. 137). "Categoria deve ser entendida aqui como o conceito sob o qual se organiza e ganha sentido tudo aquilo que os homens fazem sob uma determinada atitude" (PERINE, 1987, p. 137).

É importante pontuar que nem toda atitude humana origina um discurso. Nem toda forma de viver no mundo proporcionará uma compreensão filosófica desse modo de estar no mundo. É perfeitamente possivel existir sem que a atitude enseje uma compreensão. Existem, portanto, entre as atitudes reais - modos de viver no mundo aquelas consideradas especiais: as que formulam discursos coerentes e, com isso, compõe o discurso coerente, pelo qual se interessa a filosofia (WEIL, 2012, p. 106-107). "Nada nos impede, então de dizer que nem todas as atitudes são de igual importância para o discurso e que é legítimo e necessário voltar-se para aquelas que produzem discursos coerentes, que, se for permitido falar assim, se produzem em discursos" (WEIL, 2012, p. 107. grifo do autor).

Temos, então, uma diferença fundamental entre as chamadas atitudes reais e as atitudes puras. Tomemos mais de perto ambas para estabelecer-lhes as diferenças. $O$ individuo concreto existe no mundo conforme certa atitude, que não é necessariamente consciente, na verdade, comumente ela não o é. Essa tomada de consciência é conhecimento da atitude e sua superação quando o indivíduo toma consciência de si elevando sua atitude à categoria que lhe corresponde, ele se abre para um novo interesse e adota uma nova atitude, que será vivida - antes de ser compreendida - no discurso da categoria anterior: vivendo uma atitude que não se elevou 
à pura compreensão categorial, ele pensa e se pensa sob um discurso que ele herda. Os indivíduos retomam um discurso antigo para pensar sua atitude atual (KIRSCHER, 1992, p. 47).

Em meio às atitudes reais, portanto, destacam-se as chamadas atitudes puras, aquelas que formam discursos coerentes. As atitudes puras ou irredutiveis operam uma compreensão de si mesmas na medida em que buscam apreender conceitualmente o essencial dos seus respectivos mundos, isso em oposição a outro discurso que é encontrado no mundo. A atitude pura não se contenta em expressar-se, ela se formula positivamente na forma de conceito opondo-se a outro discurso e sustentando o que lhe é importante (WEIL, 2012, p. 107-108). "Em suma, ela apreende o essencial de seu mundo como conceito. Esse conceito, nós o designaremos sob o nome de categoria" (WEIL, 2012, p. 108, grifo do autor). A categoria pura marca o fim do percurso do conceito, sua fixação de um sistema coerente bem como o ocaso da comunidade e de sua forma de vida tida como natural (CAILLOIS, 1953, p. 286). Quando uma atitude real engendra o processo de compreensão do mundo sem misturar-se com outras e ganhando autonomia, ela se torna uma atitude pura, ou seja, formadora de uma das categorias cujo conjunto compõe a lógica dos discursos filosóficos. Trata-se das atitudes descritas na Lógica da filosofia weiliana.

O conceito de atitude se inicia na Lógica da filosofia quando se distingue entre a verdade como saber reflexivo e categoria fundamental do discurso em oposição a atitude silenciosa daquele que vive a verdade e não a expressa (KIRSCHER, 1989 , p. 163). A pureza e a irredutibilidade das atitudes mostra sua relação com as categorias: "São as categorias que determinam as atitudes puras; são as atitudes que produzem as categorias" (WEIL, 2012, p. 108). Isso porque pureza e irredutibilidade vêm do discurso essencial produzido por uma atitude. Pura é a atitude que desenvolve uma categoria pura. Será irredutivel a atitude que não permita ao adversário do discurso nenhum meio de refutação. Uma atitude pura pode ser ultrapassada por uma escolha livre que recusa o mundo que ela representa. Esse ato é incompreensivel para a atitude recusada, de modo que é igualmente injustificável no discurso do mundo assim superado. Apenas quando a atitude nova formular a própria categoria é que seu ato se revestirá de sentido; a nova categoria, em sua coerência parcial e legitimidade relativa, apreenderá, assim, aquela que fora ultrapassada (WEIL, 2012, p. 108).

Uma categoria se caracteriza por sua coerência irredutivel, por fundar um discurso efetivamente coerente em função dos seus próprios principios, daquilo que ele considera como essencial. As categorias, deste modo, são irredutiveis umas às outras; elas são incomensuráveis porque a coerência de uma é subordinada a um essencial que para outra é inacessivel (CANIVEZ, 1999, p. 93). O sentido, que é representado formalmente com a categoria, é vivido concretamente na atitude. O discurso não é criado sem conteúdo. A categoria ordena, na forma de uma coerência, uma unidade vivida (CANIVEZ, 1999, p. 94-95).

As categorias são formas de coerência discursiva definidas pelo conceito central em redor do qual cada uma delas se organiza. A sequência da Lógica apresenta as categorias pré-discursivas (verdade, não sentido, verdadeiro e falso e certeza) que explicitam os momentos lógicos da forma do discurso em geral. As categorias seguintes (discussão, objeto, eu, Deus, condição, consciência, inteligência, personalidade e absoluto) representam os diferentes pontos de vista nos quais é possivel se situar para organizar um discurso sobre a realidade enquanto sensata, ou seja, compreensivel na forma de um discurso. Com a categoria da obra inicia-se uma ruptura com o discurso, com o principio da racionalidade discursiva. Finalmente duas categorias concluem a empreitada (sentido e sabedoria), permitindo aprender reflexivamente o sentido de todo o itinerário (CANIVEZ, 1999, p. 32-33).

As diferentes categorias representam tanto pontos de vista lógicos quanto maneiras possiveis de organizar o conhecimento sobre o real de modo coerente. As categorias são irredutiveis umas às outras. Isso quer dizer que o principio em torno do qual cada uma se organiza - discussão, Deus, 
consciência moral - só é essencial para aquela categoria, sem sê-lo para as demais. Como cada ser humano que pensa sob determinada categoria, e que vive na atitude correspondente, adota um princípio distinto das demais, não há diálogo possivel entre eles (CANIVEZ, 1999, p. 61-62).

Do ponto de vista daquele que não vive a atitude que corresponde à categoria, essa não é mais que uma forma discursiva, modos de organização possivel do discurso, de questões em torno das quais o discurso filosófico volta-se para a experiência concreta para interrogá-la e interpretá-la (CANIVEZ, 1999, p. 95). Deve-se lembrar que todas as categorias - exceto sentido e sabedoria - são concretas, elas correspondem a atitudes possiveis. Apenas faz-se por bem salientar que, com exceção da atitude em que se vive e que corresponde à sua categoria, todas as categorias são formais, enquanto são puras formas de coerência. Além disso, ao fim do percurso empreendido por aquele que vive na ação, compreende o que faz sob a categoria do sentido e conhece o que almeja pela sabedoria, todas as demais categorias tornam-se formais (CANIVEZ, 1999, p. 95).

O indivíduo concreto está no mundo, que, na atitude, é compreendido como aquilo no que ele vive. E esse estar no mundo significa viver nele de determinada maneira, ou seja, segundo determinada atitude. Costumeiramente, a atitude não é consciente, não refletida sobre si mesma. Ela se realiza. Ela é o universal particular que realiza um essencial ainda não revelado, pois será o discurso que apreenderá a atitude, cuja luz revela esse essencial. Diante isso o essencial deixa de sê-lo, deixa de ser fim perseguido inconscientemente. Apreender uma atitude é libertar-se dela. A partir do momento que esse essencial é reconhecido com o que fora inconscientemente perseguido, surge outro essencial, uma vez mais o inapreensivel, o essencial do essencial (WEIL, 2012, p. 106).

Esse movimento de apreensão do essencial de um mundo como discurso é o que corresponde à categoria (WEIL, 2012, p. 108). Não obstante, essa tomada de consciência da atitude, a categoria não ocorre necessariamente. O individuo pode ater-se à sua atitude, julgando a partir desse ponto de vista tudo o que lhe chega (WEIL, 2012, p. 106). "Para o homem concreto, todas as atitudes são equivalentes, isto é, absurdas, exceto uma, a sua, que não é da alçada de nenhum tribunal, mas constitui o tribunal em que tudo é passivel de julgamento" (WEIL, 2012, p. 106).

O descontentamento do homem em uma atitude está na raiz da passagem de uma categoria para outra. A violência aqui desempenha um papel fundamental, ${ }^{4}$ entretanto, esse descontentamento do homem com um mundo superado e sua recusa livre desse mundo não devem ser confundidos com o descontentamento da obra, por exemplo, e sua rejeição da razão. Quando o mundo de um determinado discurso não mais contenta o indivíduo que está diante desse discurso, esse mundo superado é apreendido no discurso mesmo originado por esse mundo, 5 como um mundo violento, no qual o homem que o habita pode achar-se descontente. Abre-se aqui o ensejo para um discurso que se pretende novo, e que separa o indivíduo do antigo mundo, transformado em outro do homem, ou seja, em violência. Instaura-se aqui a ruptura; antes dela, o descontentamento gera a cisma. Violência que faz o homem sentir violentamente a falta de contentamento no antigo mundo; violência que origina um discurso e assim produz a filosofia (WEIL, 2012, p. 112-113).

Esse descontentamento gera um movimento histórico capturado pela filosofia, movimento esse que é revolta violenta do sentimento. Trata-se de uma revolta contra condições interiores e exteriores, ocasionada pela promessa não realizada subjacente a todo discurso humano: o contentamento, ou seja, a presença do incondicionado, quando o homem não se sentirá mais como ser

\footnotetext{
4 "É a violência que, época após época, dá a si mesma, no discurso, o que ela pode negar e que, ao se apreender como liberdade em seu discurso e, ao mesmo tempo, contra seu discurso, produz a filosofia" (WEIL, 2012, p. 113).

5 A partir do discurso que o homem encontrou no mundo que ele se opõe a esse mundo e a esse discurso. Permanecendo preso aos conteúdos concretos desse discurso, tudo o homem recebe dele, inclusive a forma concreta do descontentamento e da revolta expressos e sentidos como tais por si (WEIL, 2012, p. 114).
} 
condicionado. A promessa da eternidade da presença existe apenas no tempo da história. Cada discurso porta a mesma promessa e compreende a si mesmo como eterno, pois se propõe erradicar a violência definitivamente para que o homem que vive sob a égide do seu mundo alcance o contentamento (WEIL, 2012, p. 113).

O ser humano vive no mundo formado por uma categoria, por uma certa forma de discurso que constitui a verdade desse mundo; é possivel aceitar essa verdade, contentar-se com ela, ou se pode senti-la como insatisfatória ou insensata. Nesse caso, ele pode inaugurar uma nova forma de pensar, adotando uma atitude que se opõe àquela categoria. Se essa atitude é pura, ou seja, que é possivel adotar e que se explicita em um discurso coerente, ele descobre uma nova categoria (CANIVEZ, 1999, p. 86). A passagem de uma categoria para outra é livre, caracterizando-se, assim, como uma ruptura, porém, essa ruptura não quebra o desenvolvimento do discurso e sim fornece o princípio da sua progressão lógica, cujo exemplo mais radical aparece na oposição entre o absoluto e a obra. Cada categoria trata de uma forma de coerência que deixa margem à revolta, a um protesto da liberdade, por meio do qual o indivíduo pode recusar certa forma de verdade, no momento em que ela o deixa insatisfeito (CANIVEZ, 1999, p. 83).

\section{Retomadas, sentido e sabedoria}

A retomada é um conceito weiliano essencial, ${ }^{6}$ pois é graças a ele que se opera a unidade entre lógica e história, a apreensão do novo em uma linguagem antiga, a única disponivel para aquele que já ultrapassou aquilo que essa linguagem exprime; graças à retomada, uma nova atitude se compreende sob uma categoria anterior (QUILLIEN, 1970, p. 414). A retomada não se trata de recuperar uma forma de vida antiga, mas sim de dar forma ao discurso coerente na linguagem essa forma de vida fala, para compreender uma atitude nova que suscita uma interpretação (KIRSCHER, 2013, p. 31-32).
Em um primeiro sentido, a retomada se dá quando uma atitude se exprime em uma linguagem que não é a sua, mas a de uma categoria anterior. No presente caso, a atitude do indivíduo que se opõe ao mundo formado por um certo tipo de discurso não se exprime na linguagem que lhe é adequada, ela começa então a utilizar a linguagem do seu mundo, por exemplo, para se justificar em termos que sejam compreensiveis aos seus contemporâneos, ${ }^{7}$ justificando-se aos olhos dos outros homens utilizando a linguagem que ultrapassa. Em um segundo sentido, a retomada significa o modo como as categorias de todo discurso são, em cada caso particular, retomadas sob uma categoria central e combinadas em uma configuração singular. Assim, por exemplo, no pensamento de Rousseau, podemos encontrar retomadas do eu e da personalidade sob o ponto de vista central da consciência (CANIVEZ, 1999, p. 87-88).

\begin{abstract}
No início de uma nova época - no momento em que um novo interesse, ao querer destruir um mundo envelhecido, organiza um mundo novo -, é, portanto, uma antiga categoria que apreende a nova atitude e fala de uma nova categoria, e ao falar a seu respeito, também a esconde e deturpa. O homem retoma (para nós que, ao chegar mais tarde, conhecemos a categoria que ele está apenas desenvolvendo) um discurso que, em sua ação, ele já ultrapassou, e pode-se dizer que todo trabalho de uma lógica aplicada da filosofia consiste na compreensão dessas retomadas de antigas categorias que formam a linguagem e os discursos (não coerentes, embora se pretendam coerentes) dos homens (WEIL, 2012, p. 122-123, grifo do autor).
\end{abstract}

A retomada é um esquema, o que torna uma categoria aplicável à realidade e que permite assim realizar concretamente a unidade entre filosofia e história, ou seja, permite aplicar a lógica à realidade histórica, permitindo a compreensão dos discursos concretamente sustentados pela humanidade no passado e no presente (WEIL, 2012, p. 123).

O sistema que representa a coerência alcançada por uma categoria pode ser retomado em qualquer momento da história subsequente à sua elaboração. Desse modo, o indivíduo pode

\footnotetext{
6 Kirscher (2013, p. 32-33) considera que a retomada é um conceito mais fundamental e constitutivo para a lógica da filosofia do que as atitudes e as categorias. Segundo Quillien (2013, p. 48) a retomada é o conceito central e o motor da Lógica da filosofia.

Essa é a chamada função prática da retomada (CANIVEZ, 2013, p. 19).
} 
retomar essa coerência estabelecendo-se nessa categoria; sob ela o individuo retoma tudo aquilo que ele encontra em um mundo que é formado por uma ou mais categorias diferentes daquela que o indivíduo em questão adotou (WEIL, 2012, p. 125).

Essa categoria que fora ultrapassada, mas que, ao ser retomada, constitui a coerência verdadeira para aquele que o faz, constitui um motivo de revolta, o outro - ou seja, violência - para aquele que vive no mundo da categoria posterior (WEIL, 2012, p. 125). Essa nova atitude se expressa com a linguagem daquela que ultrapassa e que já se constituiu como categoria por ter formado sua própria linguagem. Como não dispõe ainda de linguagem sua, a nova atitude deve servir-se daquela que dispõe: a do mundo antigo que abandona.

Com as retomadas, que são em número indeterminado, ocorre uma reabertura do mundo compreensivel como campo da atividade filosófica (CANIVEZ, 1999, p. 98). Compreender tanto uma filosofia como um discurso qualquer significa mostrar as retomadas que ele articula e que o constituem. Cada atitude pode retomar as categorias logicamente precedentes. Assim sendo, as atitudes posteriores, mais complexas, são sujeitas a retomadas mais numerosas, mesmo a retomadas de retomadas. As indicações dadas por Weil ao final de cada categoria não esgotam a possibilidades das retomadas. (KIRSCHER, 1992, p. 47).

As retomadas podem se dar de duas formas, enquanto apreciação ou justificação. O que as diferencia é a perspectiva de cada uma. "A retomada de apreciação é efetuada do ponto de vista da categoria que está a ponto de ser ultrapassada"8 (CANIVEZ, 2013, p. 18, tradução nossa). Trata-se de uma retomada que é feita do ponto de vista da categoria que é ultrapassada. Essa categoria então tenta entender a nova atitude e profere um julgamento de apreciação sobre ela, julgamento e tentativa de compreensão que, na maior parte dos casos, são falsos (CANIVEZ, 2013, p. 18). "Ao contrário da retomada de apreciação, a retomada de justificação efetuou-se do ponto de vista da nova atitude"9 (CANIVEZ, 2013, p. 19, tradução nossa). Essa nova atitude passa a se expressar e tomar consciência de si utilizando a linguagem do mundo que põe em xeque (CANIVEZ, 2013, p. 19).

Se a retomada confere uma unidade ao empreendimento weiliano nos termos de formalidade e de história, o sentido revela a reflexão formal para si mesma (CASTELO BRANCO, 2013, 125-126). Sentido e sabedoria realizam uma reavaliação do discurso coerente que se fez necessária após as categorias da revolta. Não se trata de categorias concretas, as quais correspondem atitudes, mas são categorias formais, sob as quais se tematiza e compreende o conjunto do percurso da Lógica da filosofia (CANIVEZ, 1999, p. 80). Para compreender o movimento da lógica da filosofia weiliana, faz-se por bem passarmos pelas funções que exercem sentido e sabedoria. Comecemos pelo sentido.

O sentido formal se distingue da verdade por ser afirmação da verdade de um novo conteúdo, já que ele não possui conteúdo, e a verdade não é outra coisa que o preenchimento determinado do sentido formal (KIRSCHER, 1970, p. 394). O sentido não está em um discurso em particular, presente de diversas maneiras sem que nenhuma seja absoluta. Ele encontra-se no jogo do movimento de transcendência imanente no mundo, no homem e no discurso (KIRSCHER, 1970, p. 384). O sentido formal, categoria sem atitude que ultrapassa toda atitude-categoria, foi pensada pelo lógico da filosofia como aquilo que, em toda atitude, age e funda a recusa da verdade precedente, ou seja, como aquilo que possibilita a busca e a firmação de uma nova verdade (KIRSCHER, 1970, p. 393).

A linguagem é aquilo em que se constitui o sentido. Ela é aparição concreta da liberdade. Ela é diferente do discurso, por ser mais antiga do que tudo que o discurso produz, é também mais vasta e profunda. Ela é espontaneidade na acepção de que a linguagem não é possuida por um indivíduo, ela se $\mathrm{cria}^{10} \mathrm{~A}$ realidade e o discurso que the correspondem apenas podem

\footnotetext{
8 Do original: La reprise d'appréciation est effectuée du point de vue de la catégorie qui est en train d'être dépassée.

9 Do original: A l'inverse de la reprise d'appréciation, la reprise de justification est effectuée du point de vue de la nouvelle attitude.

10 "Não há a linguagem: todo 'haver' para o homem nasce dentro da linguagem. Só há linguagem, esta ou aquela, e a passagem de uma outra se faz na realidade da vida: não se pode saltar para dentro da linguagem a fim de chegar, como por mágica, ao universal ou à presença; seria mais fácil pular por cima da própria sombra" (WEIL, 2012, p. 593)
} 
ser separados pela linguagem. Por meio da linguagem o sentido revela-se como a categoria da filosofia (WEIL, 2012, p. 592-593).

Isso porque a linguagem não é a categoria (não mais do que o Ser o é para Aristóteles, ou a liberdade, para Kant), visto que ela não determina nenhuma linguagem concreta, mas se determina e se torna concreta nas linguagens concreta: a determinação formal da linguagem é o sentido, e é sob a categoria do sentido que a filosofia se compreende (WEIL, 2012, p. 593, grifo do autor).

A partir dai a filosofia se define como a ciência do sentido. Não se trata aqui de uma concepção de ciência como aquela que se debruça sobre um domínio limitado e objetivamente unificado. A ciência aqui é ciência do sentido, o que significa aquilo que constitui o sentido enquanto coerência de todas as atitudes reais. Além disso, por constituir a coerência de todas essas atitudes reais, a filosofia se constitui a si mesma no sentido. Filosofia é ciência do sentido pois é essencialmente o sistema no qual entra todo o sentido concreto. Esse sistema não é um sistema fechado, de modo que a criação concreta do sentido permanece em aberto, ${ }^{11}$ já que a filosofia não um modo de viver, ela apenas define a vida razoável (WEIL, 2012, p. 593-594).

Dessa forma, podemos dizer que o sentido é a forma da Lógica da Filosofia, a categoria na qual e sobre a qual vê-se toda atitude-categoria bem como ela própria (KIRSCHER, 1970, p. 377). O sentido também é compreensão da violência, posto que é categoria formal, é a autocompreensão da filosofia e do seu outro que ela compreende se compreendendo (QUILLIEN, 1970, p. 434). Enquanto categoria constitutiva da filosofia, o sentido é unidade viva, pois nela o caráter imediato do sentimento se organiza em unidade pensada, de modo que a categoria se torna aplicável à atitude. A filosofia, portanto, é busca do sentido e o sentido da filosofia é o sentido em si (WEIL, 2012, p. 606).

Trata-se aqui da categoria das categorias, que contém todas as outras: o sentido.
Em relação a esta última, as categorias são todas particulares, assim como ela própria não é nada, o vazio do impensável, sem todas as outras. É nela que as outras categorias revelam seu ser: elas são as articulações do sentido, e depois que isso foi compreendido, é de acordo com elas que todo sentido concreto (todo sistema histórico) deve ser interrogado pela filosofia que se sabe razoável (WEIL, 2012, p. 606).

O sentido será o esquema conforme o qual a categoria se torna aplicável à atitude (WEIL, 2012, p. 606). Sentido é autorrealização da filosofia que se compreende no seu outro, e se compreende também como uma das possibilidades de atualização da linguagem humana e que reconhece a autenticidade das demais. Assim, nessa categoria se compreende o sentido daquilo que o homem fala, constrói, vive, e o sentido é mundo. Sentido é consciência filosófica da filosofia (QUILLIEN, 1981, p. 1230).

Na perspectiva da lógica, o movimento da filosofia não acaba com o sentido, pois se trata se tornar a sabedoria acessivel para o homem concreto. Assim, a categoria da sabedoria apresenta a figura do sábio: aquele que, em sua existência concreta realiza o sentido. "O que era recusado sob a categoria do sentido, a saber, a vida no sentido, é aqui proposto, proposto como resultado concreto do pensamento formal, e proposto ao homem que se mantém na razão, que é discurso e ação" (WEIL, 2012, p. 614, grifo do autor). A sabedoria é, portanto, o que faz do sábio o homem da presença. A sabedoria é a segunda das categorias formais constitutivas da própria filosofia, como o sentido, não sendo uma das atitudes-categorias concretas (WEIL, 2012, p. 610-611).

Dizer que a sabedoria é categoria formal e teórica, significa chamar atenção para a possibilidade da coincidência do formal e do concreto para um indivíduo que não está fora do mundo, mas sempre em uma situação histórica determinada, que sabe que não pode renunciar à ação e ao discurso. O sábio é aquele que na sua liberdade escolhe o discurso e a ação, a sabedoria, portanto, sendo a elaboração de um discurso seja de modo tal que

11 "Ora, o filósofo não possui o sentido, mas deve elaborá-lo, e a espontaneidade se apreende apenas nas criações nas quais ela se cristaliza. A filosofia é, portanto, ciência do sentido em ambas as acepções: que visa ao sentido (concreto) e é constituida pelo sentido (formal)" (WEIL, 2012, p. 594). "A categoria do sentido se desenvolve no conceito da 'ciência da filosofia', que é a ciência do sentido, em ambas as interpretações admitidas por essa formulação: ciência que parte do sentido, formada pelo sentido, e ciência que trata do sentido - distinção na qual se reencontra aquela entre sentido formal e sentido concreto. Pode-se igualmente denominá-la ciência da unidade formal dos sentidos concretos: o sentido da existência é ter um sentido" (WEIL, 2012, p. 598). 
o homem possa, se o tiver, trabalhar para a realização de um mundo no qual esse homem possa realizar seu discurso (QUILLIEN, 1970, p. 435-436).

A sabedoria, estando presente em cada categoria devido ao fato de proporcionar unidade ao discurso (o que significa fazer a articulação do sentido em cada categoria) e da situação (o mundo real da categoria, sua atitude), de modo que, mesmo sendo categoria formal, na sabedoria, coincidem o formal e o concreto, sendo esse não o concreto do finito; o concreto do sábio é o concreto pensado (QUILLIEN, 1981, p. 1237). A ideia de sabedoria é reconciliação em um individuo concreto, universal na sua particularidade, de razão e de realidade, de discurso e ser (KIRSCHER, 1970, p. 398). A sabedoria é vida visando o sentido, toda vida vivida no sentido (KIRSCHER, 1970, p. 377).

É a categoria da sabedoria que faz a transição do formal para o concreto, de modo que o pensamento da presença se torna presença no pensamento. Isso significa que a sabedoria é o concreto pensado, a revelação do sentido. E, também, como o sentido, a sabedoria se dá relacionada com a ação. Desse modo, o homem que busca a sabedoria sabe que vive em um mundo cuja história se dá na categoria da condição (WEIL, 2012, p. 612-613).

A sabedoria é categoria formal, é sob ela que é pensada a unidade do discurso e da vida, a vida como unidade num sentido que ela não apenas cria - a poesia para aí -, mas des-vela e explicita no mundo de todos e de cada um. Mas nessa qualidade de categoria formal, ela existe concretamente, sendo concreta no homem que a pensa depois de haver pensado as outras (WEIL, 2012, p. 615).

A sabedoria é considerada a última das categorias precisamente por ser a intersecção entre o formal e o concreto, ${ }^{12}$ ambos coincidindo para o homem que se sabe homem em sua situação histórica (WEIL, 2012, p. 615).

Em outras palavras, o homem em sua situação, o homem que pensa e age no interior de um sentido concreto, sabe também que pensa essa situação e sabe, além disso, que ao pensá-la no universal formal do sentido ele deixou de se pensar para pensar; tudo tem um sentido, e a sabedoria é viver no sentido pensado (WEIL, 2012, p. 615, grifo do autor).

A sabedoria reconheceu a possibilidade da individualidade se manter como tal na violência, mas o sábio descobre que a ele é facultado manter-se como individualidade razoável. Nessa perspectiva, ele renuncia à individualidade violenta, aceitando a morte que só vivia enquanto recusa da coerência agente. É importante pontuar que isso não significa a defesa de uma morte para o mundo: o sábio não se retira do mundo, ele é sabedoria no mundo (WEIL, 2012, p. 616). "A sabedoria é a morte do indivíduo que quer se conservar na razão, ela é a vida do homem razoável" (WEIL, 2012, p. 616).

Com a sabedoria tem-se a coincidência do concreto e do formal, coincidência na qual o sentido formal se torna concreto naquele que o pensa e para ele: a sabedoria é o resultado da filosofia para o filósofo, é o ponto no qual o discurso se torna vida concreta e se dá a união o homem razoável e sua situação e com isso o sentimento deixa de ser o outro do discurso (WEIL, 2012, p. 617). A sabedoria, portanto, realiza o segredo da filosofia: ela faz desaparecer a violência do mundo.

\section{Considerações finais}

Para Weil, a oposição entre filosofia e violência resulta na oposição que a primeira faz à segunda. A resposta à violência é a origem da filosofia e a dinâmica das várias possibilidades de discursos filosóficos constitui uma lógica. Essa lógica da filosofia se dá pelo desenvolvimento das atitudes puras, que constituem categorias; essas podem ser retomadas por atitudes posteriores. Esse movimento pode ser compreendido por meio dos conceitos que expressam essa dinâmica: atitudes, categorias, retomadas. É a partir daí que a filosofia enquanto resposta ao seu problema fundamenta, o problema da violência, revela seu

\footnotetext{
12 "A sabedoria não é, portanto, o saber de um conteúdo: ela não proporciona conhecimento algum em sentido algum; ela é a atitude que não se pretende categoria, mas se sabe categoria - a categoria que já não se pretende, mas se sabe atitude, cujo saber, em ambos os casos, se sabe saber formal: categoria formal que só compreende a atitude formal na identidade formal de ambas" (WEIL, 2012, p. 618).
} 
segredo. Não se trata apenas de compreender o seu outro emprestando-lhe uma linguagem que ela desdenha, a linguagem da razão. Trata-se do esforço continuado de fazer com que a violência desapareça do mundo. Para tanto, é importante conhecer os conceitos formais nos quais a filosofia se desenvolve em sua peleja com a violência, mas também compreender de que maneira essa formalidade abre passagem para o concreto. Nessa perspectiva, o sentido, enquanto categoria das categorias, categoria da filosofia, é devidamente compreendido quando não se perde de vista sua possibilidade para uma vida dotada de sentido: a vida do sábio. Se a primeira chave do segredo da filosofia é a compreensão da violência, a segunda é o seu desaparecimento. Temos, então, sentido e sabedoria. Ambas dadas em uma lógica da filosofia.

\section{Referências}

CAILLOIS, R. Atitudes et catégories. Revue de métaphysique et de morale, n 58, p. 273-291, 1953.

CAILLOIS, R. Politique et violence chez Eric Weil. Revue de l'enseignement de philosophie, Paris, $28^{\circ}$ année, nं 5. p. 1-10, 1977.

CAILLOIS, R. La violence pure est-elle démoniaque? In: Actualité d'Éric Weil, Paris: Éditions Beauchesne, 1984. p. 213-222.

CANIVEZ, P. Weil. Paris: Sociéte d'édition les Belles Lettres, 1999.

CANIVEZ, P. La notion de reprise et ses applications Cultura: Revista de História e Teoria das Ideias, Lisboa, n. ${ }^{\circ}$ 36, p. 15-29, 2013. https://doi.org/10.4000/cultura.1762

CASTELO BRANCO, J. Democracia e linguagem. In: PERINE, M., COSTESKI, E. (org.). Violência, educação e globalização: compreender o nosso tempo com Eric Weil. São Paulo: Edições Loyola, 2016, p. 171-189.

CASTELO BRANCO, J. Retomada e sentido a base da relação entre filosofia e história da filosofia na Logique de la philosophie de Eric Weil. Cultura: Revista de História e Teoria das Ideias, Lisboa, n. ${ }^{\circ}$ 36, p. 123-135, Lisboa, 2013. https://doi.org/10.4000/cultura.1815

COSTESKI, E. Atitude, violência e Estado mundial democrático: sobre a filosofia de Eric Weil. São Leopoldo: Unisinos/ Fortaleza: UFC, 2009.

KIRSCHER, G. Absolu et sens. Archives de Philosophie, Paris, $n^{\circ} 33$, p. 373-400, 1970.

KIRSCHER, G. Eric Weil ou la raison de la philosophie. Paris: Presses Universitaires du Septentrion, 1999
KIRSCHER, G. Figures de la violence et de la modernité: Essais sur la philosophie d'Eric Weil Lille: Presses Universitaires de Lille, 1992. https://doi.org/10.4000/ books.septentrion.72869

KIRSCHER, G. La philosophie d'Eric Weil. Paris: Presses Universitaires de France, 1989

KIRSCHER, G. "Le debut est dans la reprise". Cultura: Revista de História e Teoria das Ideias, Lisboa, n. ${ }^{\circ} 36$, p. 31-45, 2013. https://doi.org/10.4000/cultura.1774

PERINE, M. Filosofia e violência: sentido e intenção da filosofia de Éric Weil. São Paulo: Edições Loyola, 1987.

QUILLIEN, J. Discours et langage ou 'Logique de la philosophie'. Archives de Philosophie, Paris, $n^{\circ} 33, p$. 401-438, 1970.

QUILLIEN, J. De la sagesse comme fin de la Logique de la Philosophie: Sens et présence, poésie et philosophie. Annali della Scuola Normale Superiore di Pisa, Pisa, volume XI, n. ${ }^{\circ}$ 3. p. 1223-1242, 1981.

QUILLIEN, J. La reprise, Kant, Marx. Cultura: revista de História e Teoria das Ideias, Lisboa, n. ${ }^{\circ}$ 36, p. 47-61, 2013. https://doi.org/10.4000/cultura.1781

SCHOPENHAUER, A. As dores do mundo. São Paulo: Edipro, 2014.

TOSEL, A. Action raisonnable et science sociale dans la philosophie d'Éric Weil. Annali della Scuola Normale Superiore di Pisa, Pisa, volume XI, n 3, p. 1157-1186., 1981.

WEIL, E. Lógica da filosofia. São Paulo: É realizações, $2012 a$

WEIL, E. La philosophie est-elle scientifique? Archives de Philosophie, Paris, n. 33 , p. 353-369, 1970.

WEIL, E. La culture. Philosophie et réalité II. Paris: Beauchesne Éditeur, 2003.

\section{Daniel Benevides Soares}

Doutor em Ética e Filosofia Política pela Universidade Federal do Ceará (UFC), em Fortaleza, CE, Brasil; professor da Faculdade Católica de Fortaleza (FCF) em Fortaleza, CE, Brasil; membro do Grupo de Trabalho (GT) Eric Weil ea Compreensão do Nosso Tempo, da Associação Nacional de Pós-Graduação em Filosofia (ANPOF).

\section{Endereço para correspondência}

Daniel Benevides Soares

Faculdade Católica de Fortaleza

Rua Tenente Benévolo 201

Centro

CEP 60160-040

Fortaleza, CE, Brasil 